\title{
IT applications in the quality management of Hungarian meat product chains
}

\author{
István Füzesi ${ }^{1}$, Miklós Herdon ${ }^{2}$
}

\section{N F O}

Received 29 March 2010

Accepted 19 May 2010

Available on-line 31 May 2010

Responsible Editor: K. Rajkai

\section{Keywords:}

quality management, meat industry, food tracing, information system

\begin{abstract}
$\underline{\text { A B S T R A C T }}$
The manufacture, distribution and retailing of foodstuffs became an extraordinarily complex business activity. The complete food chain must provide for the implementation of the strictest quality standards and safety regulations. Problems of food safety can be solved by keeping (and enforcing) applicable regulations, by introducing modern quality assurance systems, by making possible the traceability of products and their identification. The safety of product lines and tracing of products cannot be solved without using information systems in a certain level. Our research focused on the IT support and development of quality management systems in the Hungarian meat industry, especially on food tracing systems, and on the utilized identification systems. In the framework of our research, we developed a research portal that presents the results about the meat industry. The portal refers also to planned modern quality control and tracing systems and to the publication of the knowledge base connected with the topic. In our study, it came to light that, agrarian traceability struggles with many more problems in general. Companies try to live up to expectation, but they often apply different solutions with totally different approaches, while serving several different market aspects, depending on their customers.
\end{abstract}

\section{Introduction}

Increasingly, consumers tend to worry about the safety and origin of foods. Recent scandals related to the safety and origin of foods, sometimes overemphasized by the media, have fundamentally shaken consumers' confidence in foodstuffs available at shops (Lakner et al., 2005). The manufacture, distribution and retailing of foodstuffs became an extraordinarily complex business activity. This extraordinary complexity makes it necessary to develop overall controlling processes that are indispensable if we want to safeguard the quality product of safe and excellent foodstuffs (Lang and Heasman, 2004). With this background, the complete food chain must provide for the implementation of the strictest quality standards and safety regulations. Therefore, in every phase of the food chain, from the purchase of raw material through manufacture and distribution to the sales, the quality demands up to the actual products, processes and handling methods should be fulfilled. At the same time, since consumers do not really have an overlook of the technology and circumstances of product, only confidence in a manufacturer can help in choosing his food. Problems of food safety can be solved by keeping (and enforcing) applicable regulations, by introducing modern quality assurance systems, by making possible the traceability of products and their identification - beyond any doubt. The safety of product lines and tracing of products cannot be solved without using information systems of a certain level (Schiefer, 2008). In any case, one could greatly improve the level of food safety and the information supply by installing the newest technologies and IT facilities at every participant in a product line in the meat industry.

\section{Objectives}

Our research focused on the IT support and development of quality management systems in the Hungarian meat industry (as refers to meat industrial product enterprises, while the poultry industry is also involved) especially food tracing systems, utilized identification systems and those which may

\footnotetext{
${ }^{1}$ István Füzesi

University of Debrecen, 4032 Debrecen, Böszörményi út 138., Hungary

fuzesii@agr.unideb.hu

2 Miklós Herdon

University of Debrecen, 4032 Debrecen, Böszörményi út 138., Hungary

herdon@agr.unideb.hu
} 
become applicable in the future. We also studied information technology tools and examined the establishment of domestic meat industry enterprises. On the basis of the results of our examinations, we set out to elaborate a cost-efficient device and to offer a system that might assist meat industrial enterprises to choose an applicable quality system, while ensuring effective product identification and tracing, taking into consideration the advantages of introducing such a device. More specifically, the aims of our research were the following.

Regarding to regulations, standards referring to product qualification and product identification, we set the following targets: to treat and systemize the standards and specifications applied primarily in meat industrial product chains, as well as to determine which of these are relevant. First, we considered which of the composite Hungarian and EU standards, directives and orders are pertinent to our areas of study. We assumed that the up-to-date of the applied quality control system must be connected with the economic development of the company, its place in the product chain and its market position.

The types of identification technologies and the respective supporting technological systems may differ within a specific product chain, depending on the nature of manufacturing from raw materials to the point in time when one has produced a finished article. Moreover, the applied technologies might be influenced by a number of factors. These include the environment, economic factors, the quantity of to-be-stored information connected to the product or the systems of product and manufacture. Our objective is to explore, systemize and analyze those identification technologies that are applicable for meat industrial product lines, and may serve as the basis for further research.

As a next objective, we wished to explore the requirements of product tracing, the levels of tracing, its organizational and economic background, as well as its realization at the various steps of the meat industrial product line. Of the steps on the product line, we wish to focus first of all tracing of forages, questions of livestock tracing and the area of processed products. Considering this, we primarily wish to analyze meat plants, based on questionnaires, personal visits at plants and in depth interviews.

The next target of our research is the exploration of information systems at meat industry companies. More specifically, we examine the question of product tracing there. In the cases of medium and larger size meat industrial companies, the running of information systems (integrated information systems) is essential. We primarily focus on that group of companies and enterprises, where product tracing functions have been integrated. Research of central (national, sectoral) information systems providing for food safety, food chain supervision and the realization of withdrawal of products is indispensable in our paper and because of their link with different steps of any chain of products. Investigation of these links comprises livestock identification, central registers linked with the field of breeding, as well as most importantly with the Rapid Alert System for Food and Feed.

Finally, we developed a research portal on the Internet connected in part with the above-mentioned areas of interrogation, and in part with the aim of gathering information and publishing the results for use by plants and experts.

\section{Applied methods}

We began to study food safety and tracing systems and to explore identification technologies, as well as to analyze product tracing through information systems. In spite of the fact that the secondary research is the major starting-point of the investigation, thorough professional interviews and consultations were indispensable, in order to produce the case studies. We visited many meat plants to test the solutions used in the sector in practice. In the course of the in depth interviews, we familiarized ourselves with the applied technologies and systems, we gained information on the theme of the research portal and we held dialogues with quality assurance and IT experts about questions of content and the methodology of the questionnaires.

It was necessary to consistently describe all the tasks to be done by the enterprises with their contentual and temporal dependences. For this purpose, we used the ARIS business process modeling and planning software system to analyze the business (production) processes and to describe them in 
our study. During our research work, we used ARIS Designer 7.0 to model processes and to determine and describe the main control points of product tracing.

Our questionnaire was sent to 467 Hungarian companies and we received 97 answers which mean more than 21 percent response rate. Thanks to the large number of responses, the sectoral distribution of the companies in the full pattern and in the response pattern showed a similar arrangement. The Internet version of the questionnaire was prepared by the open source Limesurvey software system. We stored the questionnaires and the data in a MySQL database, and then converted the answers into a form that can be processed by the SPSS program packet. The evaluation was made in the same way. Methods of comparing analysis have been used by system selection, and by comparing the evaluation of different identification and tracing techniques.

\section{Major research results}

\subsection{Professional information service of the research portal}

In the framework of our study, we developed a research portal that supported research work applied in the meat industry, specifically pertaining to planned modern quality control and tracing systems and to the publication of the knowledge base connected with the topic. In preparing the portal, we had quite a couple of aims. On the one hand, we wanted to summarize at one place the most important knowledge, concerning the topic, especially which is difficult to access in Hungary, or which would require significant research in the literature and in the Internet. On the other hand, the questionnaire which we compiled and sent to meat industry enterprises, could be filled in an electronic way through the portal. Indeed, the results of the survey can be viewed there, too.

On the portal, information can be found in many topics:

Technologies. At this menu item, we gathered the most relevant articles concerning identification techniques, as well as brochures, companies dealing with the solutions, and a further collection of professional portals in the field of identification.

Issues. It is collection of publications and literatures referring to the topic. By means of the presented books, anyone can access detailed information about quality management, tracing, food safety and modern identification techniques. Selecting among the publications is assisted by a short summary of every literature item, located next to the basic data.

Publications. On this site, we listed the publications of the Department of Economics and Agricultural Informatics issues on this subject, as well as the papers and theses presented at scientific students' conferences.

Regulations. This site comprises collection of standards, orders and regulations. Here can be found links, necessary to cognition of the respective compulsory, voluntary commercial standards referring, to meat industry and references to pages comprising detailed descriptions.

Links. It comprises of the availability of organizations and authorities acting in domestic and international meat and food safety.

\subsection{Usage of quality management systems}

Today, we can say that all food companies in Hungary have implemented a system of quality management. We considered relevant to examine, which systems are used by meat industry enterprises in Hungary at specific levels of product lines (Table 1). In implementation of the systems, one can produce goods of better quality. Furthermore, there is a strong pressure from food companies on suppliers to meet the expectations and regulations of the European Union, which is also not incidental (Sembery, 2000). This can be seen from our survey: all of the companies use HACCP, although this result is not surprising, since its application became compulsory in 2002. Usage of GXP regulations and commercial standards depends greatly on the level of product chain, where the firm is. Generally, one can also say that usage of TQM and ISO 22000 systems is very rare, unfortunately. Applying quality management systems does not show a great variation at the steps of meat industrial product line, except of the following cases: 
At companies acting in breeding application of systems (IFS, BRC) in trade is obviously low, because mostly they are not directly connected with trade chains, unless they have other activities, which make the establishment of such a relationship necessary. In parallel, by increasing the process level, the usage grows.

At companies, dealing with the sale of ready-to-cook articles, usage of ISO standard is growing; in the same way, that will cease usage of GXP systems. We found interesting to explore the proportion of applying quality management according to revenue, because introduction and audit might be costly, so firms may be influenced by this.

Table 1. Usage of quality management in the product chain

\begin{tabular}{|c|c|c|c|c|c|c|}
\hline & HACCP & $\begin{array}{c}\text { GMP, GHP } \\
\text { reference books }\end{array}$ & $\begin{array}{c}\text { ISO 9000 } \\
\text { regulations }\end{array}$ & BRC, IFS & TQM & $\begin{array}{c}\text { ISO } \\
22000\end{array}$ \\
\hline Stock-raising & $100 \%$ & $7 \%$ & $40 \%$ & $13 \%$ & $7 \%$ & $7 \%$ \\
\hline $\begin{array}{c}\text { Livestock buying } \\
\text { up }\end{array}$ & $100 \%$ & $12 \%$ & $36 \%$ & $28 \%$ & $4 \%$ & $8 \%$ \\
\hline Slaughtering & $100 \%$ & $8 \%$ & $27 \%$ & $27 \%$ & $3 \%$ & $11 \%$ \\
\hline \begin{tabular}{c} 
Food processing \\
\hline $\begin{array}{c}\text { Distributing of } \\
\text { oven-ready } \\
\text { products }\end{array}$
\end{tabular} & $100 \%$ & $11 \%$ & $35 \%$ & $30 \%$ & $3 \%$ & $7 \%$ \\
\hline
\end{tabular}

According to our expectation, we can state that with an increase in revenue, the number of systems in use also increases (Figure 1), although in cases of companies with revenues between 100 and 500 Million Hungarian Forints, a repeated setback can be seen. This phenomenon requires further examination. (Inside the certain revenue category, the number of answers was distributed fairly moderated, so variation of fit cannot explain unexpected results.)

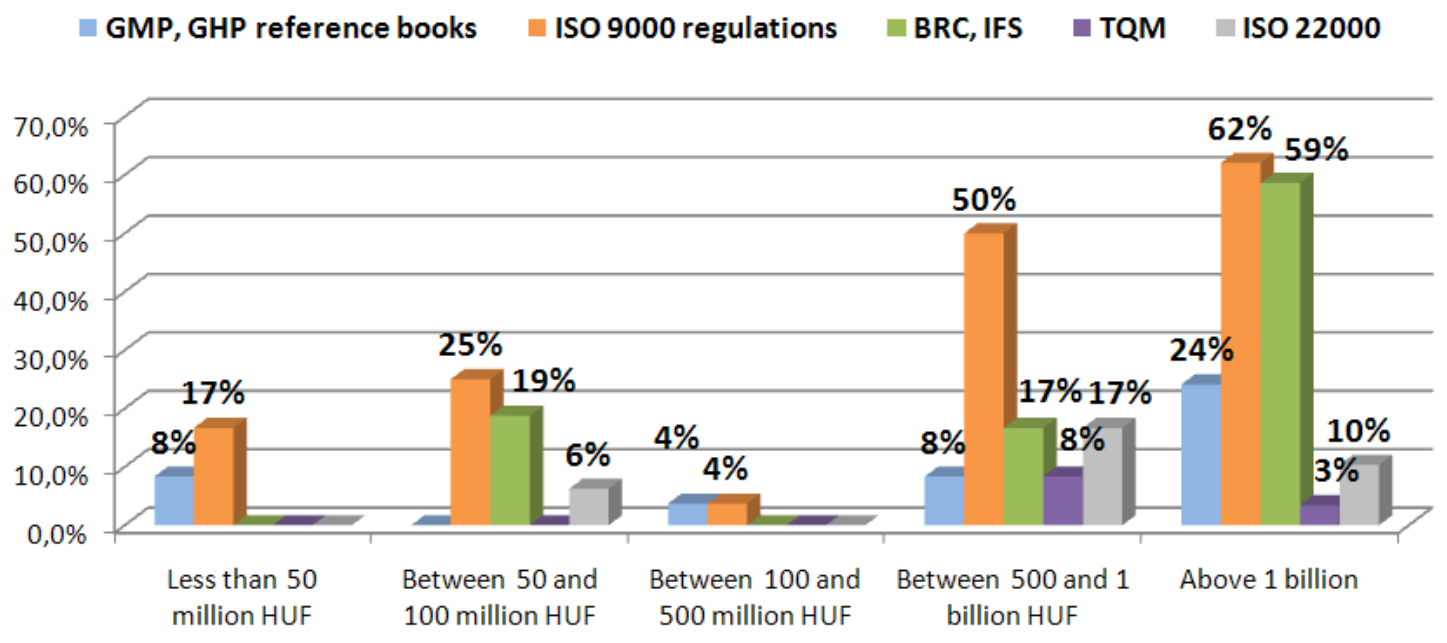

Figure 1. Usage of quality management systems according to revenue

\subsection{Adaptation of identification technologies in meat industry product chains}

A full traceability of products can be realized by the adaptation of ID labelling and bar code systems, as well as by electronic and biological marking systems, on the basis of their appropriate combination. The regulations of identification provide for the continuity and reliability of tracing among independent partners (a common language and the compatibility of information are necessary). In order to assure that the tracing from producers to consumers effectively works at each step, the information referring to the product must be forwarded together with other attached information. 
Through the quick development of computer technology, a number of new and innovative methods have been elaborated to solve this problem (Podgornik et al., 1994).

In the course of our questionnaire, we also examined product identification technologies that are usually a factory ID or bar codes. There was no undertaking with radio frequency identification among those replying (although we know about companies using this technology). Therefore, we concluded that incidence of the technology is low at present. In order to compare the identification technologies, we have to consider several factors. Considering the numerous advantages and disadvantages for each solution in comparison with the other techniques, we still cannot unanimously choose the one that conforms to the requirements of the meat industry product chain the best there are different challenges on each step of the product chain.

There are two major factors for the spreading of the new identification technologies:

One of these is the obviously high cost. The price of biological identifiers RFID and DNS-based identifiers decreased significantly in last years. The cost of identifiers per product (sometimes per kg) would allow for their usage, but meat industry enterprises are often unable to pay the required investments, beyond the costs of identifiers attached to the products. Therefore, we also need decoding of information and the development of an infrastructure that is able to decode, and to prepare the information systems and develop human resources. Consequently, with respect to the present income relations of the branch, the turnover is too long.

On the other hand, modern identification techniques allow significant advantages over traditional solutions, if their usage accompanies the with whole product chain. At present, the most different solutions are used on those steps of the chain which are mostly incompatible. The systems cannot be harmonized or with difficulties, and there is often a need for a new coding.

New standards are needed. The modern identification techniques have to increase the efficiency of processes in a way that fits the information systems for both the enterprise and for its partners. Currently, there are even several parallel standards for a given ID. The penetration of these techniques greatly depends on the uniformization of standards, which would make interoperability through the entire product chain possible. The integration of mobile and wireless technologies are also important (Szilágyi and Herdon, 2006). Mobile phones and other portable devices greatly help RFID technology becoming widely used. By using a wireless connection, we can always accurately log and if needed modify product information (by scanning an RFID label or a bar code), no matter where we are in the product chain.

\subsection{Food traceability}

To be able to withdraw the product in question from a market in the case of a food problem, one has to dispose of appropriate information, referring to each ingredient and to each manufacturing processes. In the course of a questionnaire, we examined what kinds of data Hungarian enterprises have about their products (Figure 2). The results show us that the largest defect in the re-traceability chain is in the traceability of forages. 29 per cent of the inquired firms do not dispose of any information about forages of the livestock. During our research, it came to light that, agrarian traceability struggles with many more problems in genereal. In the cases of the other ingredients, one can talk about the present levels, since an effective product withdrawal exists only if all of participants in the product chain has a clear knowledge about the origin of his products.

The number of product withdrawals increases towards the end of a product chain (Figure 3). Nevertheless this is not a surprising result. On the one hand, problems with a foodstuff can be sensed most often by the consumers; on the other hand, the more ingredients has a certain product, the more manufacturing processes it has undergone. Therefore, the chance of various problems is also greater. 


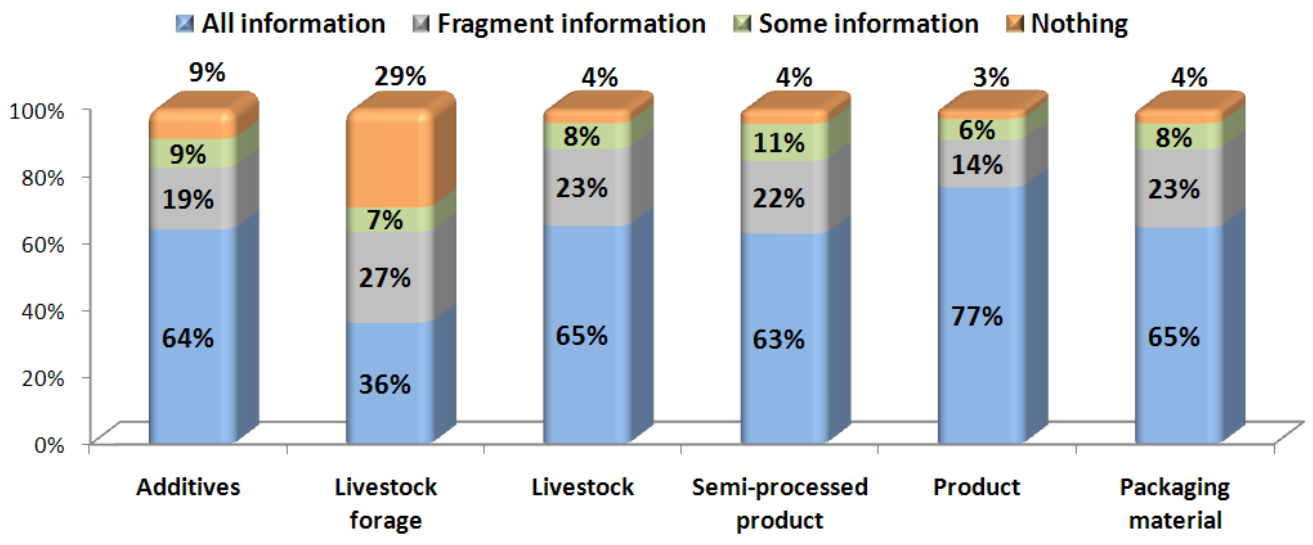

Figure 2. Available information of meat products

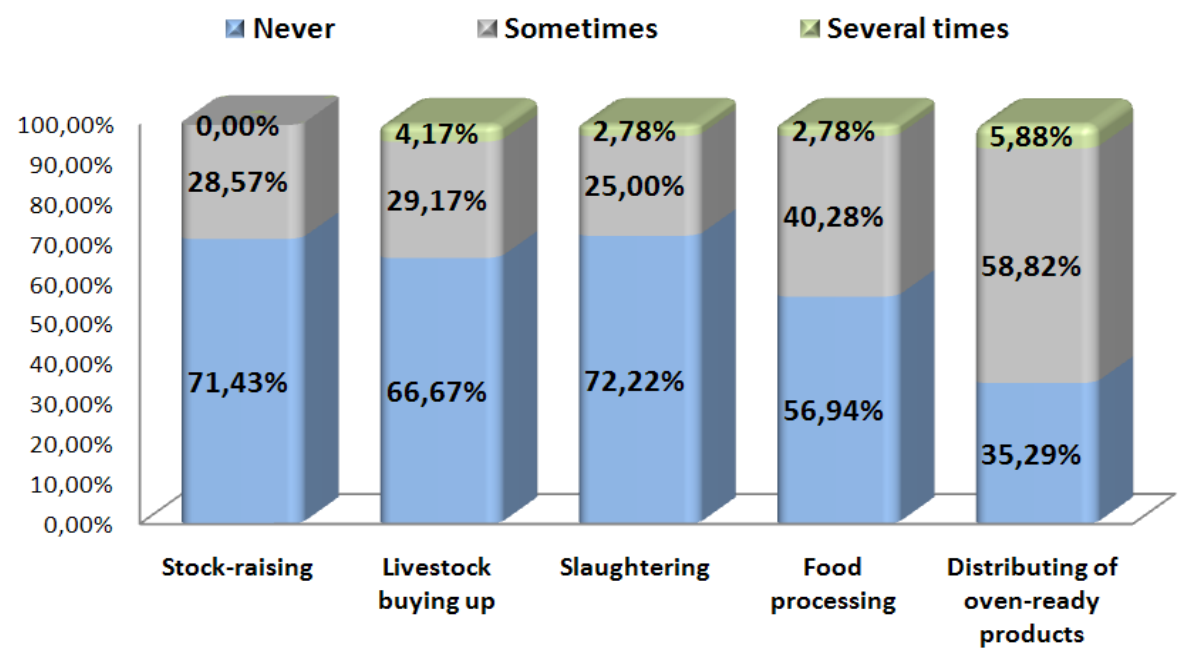

Figure 3. Proportion of food withdrawals at certain levels of a product chain in meat industry

We came to an interesting result when we defined the depth of tracing data (Figure 4). 53 percent of Hungarian firms dispose of traceability data displayed for certain products, the registration of which is without any doubt the most expensive however, the product withdrawal can cost much less since one only has to withdraw those products with a problem from the market and not a greater amount. In our experience, this number may be fairly high, so the question has not been understood properly.

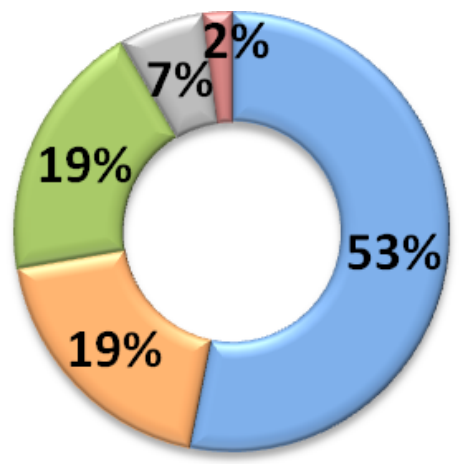

$\square$ Each product

$\square$ By slaughtering

$\triangle$ Daily

$\square$ By shift

Q Ohter

Figure 4. Depth if the tracing data 


\subsection{Usage of information systems at meat industry enterprises}

It becomes clear from our survey done in Hungarian meat industrial enterprises that integrated management systems may only be affordable for companies with high revenues. The licensing and introductory budget of these (e.g. infrastructure, training shaping) in most cases cost 10 Million Hungarian Forints. Obviously, this is practically unaffordable for small companies and would mean an extremely long cost recovery period. It is univocal from our survey how many from the total meat industrial enterprises use individual and/or integrated systems (Figure 5). We can see that companies using part modules and island solutions are in the majority. This is why we considered it important to analyze the quality management, tracing and information systems of small enterprises.

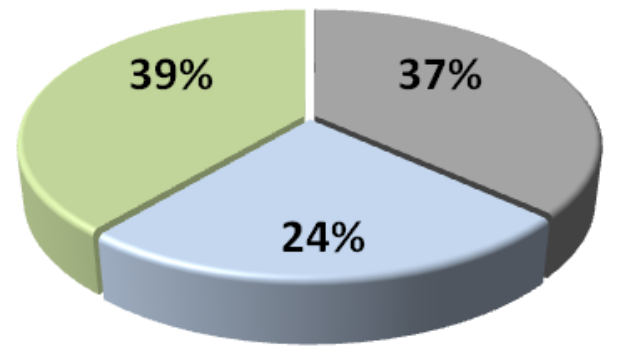

国 Individual, separated systems

田 ERP systems

\section{$\triangle$ Nothing}

Figure 5. Using information systems in Hungarian meat industry

We examined how the usage of information systems at meat companies changes according to revenues in Hungary (Figure 6.) Based on the results, less information systems will be used in the category of least revenues, 63.6 percent of companies do not have a system at all. In companies above 1 Billion Hungarian Forints, this number hardly exceeds 10 percent; in such cases, integrated company management is used to a great extent (half of the repliers). In the other groups, mixed results were obtained, but generally we can state that using individual island solutions is frequent in various types of companies. These will rather be used in the fields of stock economy and finances. For usage of integrated company management, the picture is fairly complex, too. Mainly Microsoft Navision and CSB systems are characteristic, while some actors run programs developed by themselves. From among other systems, one can mention one or two examples.

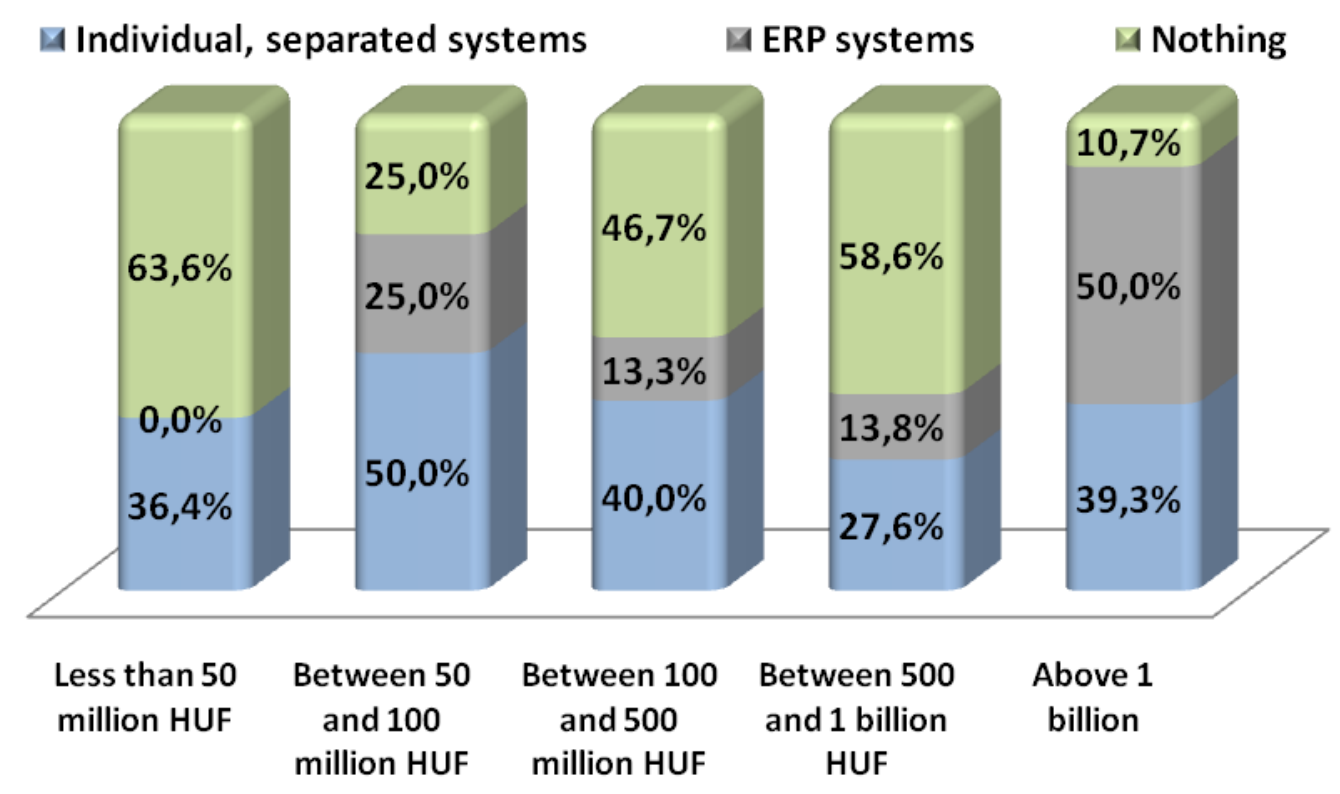

Figure 6. Usage of information systems according to revenues 
The domestic agriculture economy urgently needs innovation processes, as well as fundamental and supporting innovation processes that would improve its positions among competitors, which have shattered in the last past years. Dealing with the topic is repeatedly reasoned by the fact that the 20072013 development policy of the EU may decisively influence the long term result of the competition among nations and community of nations (Husti, 2007). This is the reason why we inquired how much the enterprises spend from their yearly revenues on the improvement and maintenance of their informatics systems, and if they plan such investments, what the volume of the investment is.

\section{Future research directions}

Several approaches have been developed in order to achieve a collaborative network. However their focus is mainly on technical aspects, related to inter-organizational communication. The serviceoriented architecture (SOA) as "a set of components which can be invoked, and whose interface descriptions can be published and discovered" does not take into consideration the service architecture. Technical interoperability concerns technical issues related to E-communication (e.g., issues on linking applications and services addressing aspects related to interfaces; ICT platforms; information integration; exchange and accessibility; security, standards; services) but this is not enough to achieve the best solution in business applications. Information /knowledge interoperability has to focus on the following aspects: information/knowledge representation and management, learning ability, rights to access information, knowledge sharing, aspects related to adaptation and recombination of knowledge in a collaborative network during its life-cycle (Chituc at al., 2007). The technical architecture of KodA is based on SOA and subsequently consists of three basic layers: business process management layer, business services layer, business application layer. The KodA focuses on the supply chain for processing food products which was communicated and discussed at different forums. This has resulted in establishing the agriXchange group that has the objective of harmonizing agricultural data exchange on a European level (Wolfert at al., 2009). In Hungary, a new, generic knowledge representation of process systems, embedded in a new cooperative system architecture seems to be an interesting background for the further development in this field (Csukás, 2009). The interoperability can be supported by different technologies which are needed for cooperation in the food chains. These new research and development directions are the Internet of Things, Digital Business Ecosystems and Cloud Computing,

\subsection{Internet of Things}

Internet of Things (IoT) is an integrated part of Future Internet and could be defined as a dynamic global network infrastructure with self configuring capabilities based on standard and interoperable communication protocols, where physical and virtual "things" have identities, physical attributes, and virtual personalities, use intelligent interfaces, and are seamlessly integrated into the information network. The Internet of Things allows people and things to be connected Anytime, Anyplace, with Anything and Anyone, ideally using Any path/network and Any service. This implies addressing elements such as Convergence, Content, Collections (Repositories), Computing, Communication, and Connectivity in the context where there is seamless interconnection between people and things and/or between things and things so the $\mathrm{A}$ and $\mathrm{C}$ elements are present and addressed.

The regulations for traceability of agricultural animals and their movements require the use of technologies like IoT, making possible the real time detection of animals, for example during outbreaks of contagious disease. Moreover, in many cases, countries give subsidies depending on the number of animals in a herd and other requirements, to farms with cattle, sheep, and goats. As the determination of the number is difficult, there is always the possibility of fraud. Good identification systems can help minimize this fraud. Therefore, with the application of identification systems, animal diseases can be controlled, surveyed, and prevented. Official identification of animals in national community, and in international commerce is already in place, while at the same time, identification of livestock that are vaccinated or tested under official disease control or eradication is also possible.

With the Internet of Things, single farmers may be able to deliver the crops directly to the consumers not only in a small region like in direct marketing or shops but in a wider area. This will 
change the whole supply chain, which is now mainly in the hand of large companies but can change to a more direct, shorter chain between producers and consumers later on.

\subsection{Digital Business Ecosystem}

The Digital Ecosystem is: unlike a client-server architecture, where the communication is centralized and which acts as a command and control environment; unlike a Peer-to-Peer architecture, where, at any time, each agent has a well defined role (i.e. client or server, but not both); unlike a Grid architecture, which stitches partners together for resource sharing but cannot avoid counter free riding; unlike a Web service network, where brokers are centralized and service requesters and providers are distributed in a hybrid architecture that does not guarantee trust and QoS. A Digital Ecosystem instead is an open community, and there is no permanent need for centralized or distributed control or for single-role behavior. In a Digital Ecosystem, a leadership structure may be formed in response to the dynamic needs of the environment. An agent in a Digital Ecosystem can be a client and a server at the same time. In the same message, agents may offer a service to others as a Server and request help as a Client. There is no centralized control structure or fixed role assignment. There is no preconfigured global architecture, where the communication and collaboration is based on swarm intelligence: Unlike traditional environments, digital ecosystems are self-organizing systems which can form different architectural models through swarm intelligence, where local interactions between agents determine the global behavior.

\subsection{A prototype tracing solution based on DBE Concept and Toolset}

IT solutions of the food chain traceability could be based on DBE solutions. One of the most important properties of this method that all data is stored in the owner database and the data is served if it is requested by the authenticated DBE server. All connected nodes have own database are stored in their own database server. Forasmuch many organizations have exiting information system (ERP), where they store the necessary data. We assure possibility to connect other existing systems to the DBE by XML technology. We use the portability property of the XML. The database structure is available for download and use. In case of the traceability the XML file contains the following information: Company name, TRU (Traceable Resource Unit) identification number, Output ID., Input ID. In addition, we need a web server where the portal software is running. The portal prepared with open source tools according to DBE principles. The prototype system is suitable for both topdown and bottom-up tracking and tracing. The working methods are the follows:

Top-down: You can see a text field on the website. You can type or scan the barcode by the help of a barcode scanner. The web server can identify the producer by the barcode. Certainly, it works only if the company has joined the community and their barcodes are stored in the database. We can reach the data which are stored in the ERP system by the product's barcode. The data show us the ingredients of the product. Inputs displayed on this page, so that the input supplier of the database searches the details of ingredients and send to the server for further processing and display, and then recursively to the product suppliers to get the similar information. We can reach the bottom level of the supply chain. It looks like a tree-structure.

Bottom-up: The knowledge of the barcode of lowest level of basic ingredient we can get besides of the basic details we can know the place of the deliveries as well. Then, either of the products manufactured by the companies which are on the $\mathrm{N}-1$ st level will be chosen which contain the ingredient of the company on the Nth. level. This goes on, until we reach the top level. Where we get the oven-ready products, which contain the basic ingredient.

With this prototype we have an opportunity to trace the full path of life of the product, if only all participant have been joined to the community. The above solution can greatly facilitate the precise monitoring the flow of substances occurring in food. Thus, the appearance of any food safety hazard we have opportunity to achieve rapid and efficient product recall. 


\subsection{Cloud Computing}

Cloud computing is a way of computing, via the Internet, that broadly shares computer resources instead of using software or storage on a local PC. Cloud computing is a by product and consequence of the ease-of-access to remote computing sites provided by the Internet. It is a paradigm shift from current use of PC's, whereby details are abstracted from the users who no longer have need of, expertise in, or control over the technology infrastructure "in the cloud" that supports them. Cloud computing describes a new supplement, consumption and delivery model for IT services based on the Internet, and it typically involves the provision of dynamically scalable and often virtualized resources as a service over the Internet (http://en.wikipedia.org/wiki/Cloud_computing).

\section{Conclusions}

The use of quality management systems does not show any great fluctuation in the given areas, except for ISO, GXP and the systems used in trade, which depends on the levels of product processing. The bar code technique is currently the absolute leader in the sector. Although modern solutions provide numerous advantages, their profitable application is not possible for the time being. Our results provide a suitable basis for the participants of the product chain to get to know and select the technology suitable for them. We drew the following conclusions in relation to the penetration of identification technologies: Hungarian enterprises most often use some serial number, lot number or bar code; The high cost level needed for building up the whole infrastructure puts obstacles in the way of the introduction of new technologies (RFID, DNS); The penetration of these techniques greatly depends on the uniformization of standards, which would make interoperability through the entire product chain possible. The biggest rupture of the traceability chain exists in the tracing of forages, $29 \%$ of interviewed enterprises have no information about the feeding of live animals. Companies try to live up to expectation, but they often apply different solutions with totally different approaches, while serving several different market aspects, depending on their customers. The special needs arising in the food industry can only be satisfied by an integrated ERP system, as it is important to cover each step of the sector and not to have holes in the production chain. We established that enterprises spend less than $1 \%$ of their income on information technology investments (the average of the entire food sector), which is a very little amount spent on the implementation of developments and modernization. For this reason, partial solutions are rather frequent at enterprises, while the ratio of using new technologies is low.

\section{References}

Chituc, C.-M., Toscano, C., Azevedo, A. 2007. Towards the Creation of a Digital Business Ecosystem for the Shoe Manufacturing Domain. In: Digital EcoSystems and Technologies Conference, 2007. DEST '07. Inaugural IEEE-IES 88 - 93 Digital Object Identifier 10.1109/DEST.2007.371951

Csukás B., 2009. Cooperative Evaluation Feedback: an IT Architecture, Supporting the Sustainability. Regional and Business Studies. 1 (1) p. 49-55 (2009)

Erabuild 2006. Review of the current state of Radio Frequency Identification (RFID) Technology, its use and potential future use in Construction. ERABUILD Final Report. Available at: http://www.itbof.com/documents/Erabuild/ERABUILD_RFID_in_Construction.pdf

Husti, I. 2007. Gondolatok az agrárinnováció néhány kritikus területéről. MAG Kutatás, fejlesztés és környezet, XXI (6) évf. No. 2., pp. 5-11.

Lakner, Z., Szabó, E., Hajdú, I.-né. 2005. The 2004 paprika scandal: anatomy of a food safety problem. Studies in Agricultural Economies, 2005. no. 102. pp. 67-82.

Lang, T., Heasman M. 2004. Food wars: Battle for Mouths, Minds and Market. London, Earthscan Ltd, 365 p.

Looney, S.W. 2002. Statistical methods for assessing biomarkers. Methods in Molecular Biology, Volume 184, pp. 81-109. 
Mohan, A., Woo, G., Hiura., Smithwick Q., Raskar R. 2009. Bokode: Imperceptible Visual Tags for Camera-based Interaction from a Distance. In Proc. ACM SIGGRAPH 2009.

Podgornik, A., Štravs, R., Koselj, P., Leštan, D., Raspor, P. 1994: Bioprocess monitoring, control and data management software SHIVA. Prehrambeno-tehnol Biotehnol Rev 32., pp. 181-186.

Schiefer, G. 2008. Tracking and Tracing - A Challenge for System Organization and IT. Journal of Information Technology in Agriculture vol 3. pp 19-25.

Sembery, P. 2000. Minőségbiztosítás az agrárgazdaságban. Budapest, Müszaki Könyvkiadó, 383 p.

Szilágyi, R., Herdon, M. 2006. Impact Factors For Mobile Internet Applications In The Agri-food Sectors. In Proc. Computers in Agriculture and Natural Resources, 4th World Congress Conference 2006. pp. 252-257.

Wolfert, J., Verdouw, C.N., Verloop, C.M., Beulens, A.J.M. 2010. Organizing information integration in agri-food-A method based on a service-oriented architecture and living lab approach. Computers and Electronics in Agriculture, Volume 70, Issue 2, pp. 389-405. 